\title{
Improvement of Service in the Supply Chains of Goods in the Transport Communication "Europe- Russia" Using the Transit Potential of the Kaliningrad Region
}

\author{
E.I. Pavlova \\ Chair of International transport management and supply \\ chain management \\ Russian University of Transport MIIT \\ Moscow, Russia \\ elenaivanovna@bk.ru

\section{I.A. Mamedova} \\ Chair of International transport management and supply \\ chain management \\ Russian University of Transport MIIT \\ Moscow, Russia \\ irada-mamedowa@mail.ru
}

\author{
E.V. Cherpakova \\ Chair of International transport management and supply \\ chain management \\ Russian University of Transport MIIT \\ Moscow, Russia \\ cherpakovae@inbox.ru \\ N.V. Yakushina \\ Chair of International transport management and supply \\ chain management \\ Russian University of Transport MIIT \\ Moscow, Russia \\ paniy@mail.ru
}

\author{
E.V. Karlyavina \\ Chair of International relations and geopolicy of transport \\ Russian University of Transport MIIT \\ Moscow, Russia \\ katerinakarlj@yandex.ru
}

\begin{abstract}
Implementation of the project of development of multimodal transportations from China to Europe through ports of the Kaliningrad region has begun. One of the reasons for changing the conventional route (through the Republic of Belarus) of Chinese goods to Europe were infrastructure restrictions at the border crossing Brest-Malashevichi. JSC "United transport and logistics company-Eurasian railway Alliance" ("UTLC ERA"), in order to retain transit cargo from China to Europe, implemented a new project together with JSC "Russian Railways" and the Kaliningrad railway-a new route Chongqing (China) - Duisburg (Germany), which passes through the Kaliningrad region. Given the geographical proximity of Kaliningrad seaport in proximity to developed European countries, it was decided to create multimodal delivery container cargo transit through Kaliningrad seaport in communication, the East - West - East, bypassing the Polish section of the railway. In addition, to improve the use of transport and transit potential of the region, several routes have been developed, which are alternatives to existing ones. The implementation of measures to modernize the infrastructure and a number of organizational
\end{abstract}

decisions will reduce the time it takes the trains to pass through the territory of the Kaliningrad region, which is an additional bonus, with the help of which it will be possible to attract additional transit cargo flows. This will improve the use of existing infrastructure and improve the level of service.

Keywords: sea transportation, integration of transport systems, transport service, transit potential

\section{INTRODUCTION}

Globalization is becoming a key characteristic of the modern global economy. Its development is contingent on the blurring of national borders and the participation of countries in the international exchange of goods and services. The ongoing international exchange processes strengthen the role of separate regions and thus facilitate their transport infrastructure development. The infrastructure component of the post-industrial world, whose most important part is the transport and logistics complex, contributes substantially to the globalization process. The transport industry development is a high-priority objective for any country. It creates additional national competitive advantages on the global scale. Popular international traffic routes have emerged, spanning more than one country. Logistics service has become a 
determining factor in the construction of the supply chain of goods. The Kaliningrad region, thanks to its convenient geographical location, is actively involved in international supply chains. It is through Kaliningrad that the main material flow between the EU countries and Russia passes. For cargo transportation rail, sea, road, air transport, or mixed transportation are used. The development of infrastructure and the search for ways to improve service in the supply chains of goods are becoming highly relevant. These questions are the subject of this study.

The Kaliningrad Region is a unique territory that is a Russian outpost in Europe. Based on its geographical location, it is poised to become a link in the integrative rapprochement of Russia and Europe. The Kaliningrad Region is the only exclave in Russia with a special economic status surrounded by European countries. The region functions as a bridge connecting the countries of Western Europe with Russia, China, Kazakhstan, and others. This presents us with a broad opportunity to use the transit potential of the transport system and develop the economy of this region. The Kaliningrad Region can serve as an equal partner on the transit transportation market, offering transit resources to the transport community that meet top modern requirements. [1].

Servicing international transit brings an effective advantage in developing the transport infrastructure, technology, and economy on its territory, creating more jobs, and providing an opportunity to integrate the regional economy in the unified global economic system. Many countries in the European Union profit from their transit potential when solving political and economic tasks. At the same time, the external environment stability has a considerable impact on the competitive ability of the region as a participant in international supply chains. The macroenvironment that includes the political, economic, social, legal, geographical, and technological components is a factor shaping the entire supply chain [2].

Kaliningrad Region was chosen as the object of study because it is an international transit zone between Europe and Asia, as it is home to a large transport hub linking the air, rail, road, and maritime transport. [3].

A railroad with a track gauge of $1,435 \mathrm{~mm}$ is built in the region to facilitate foreign trade with the European countries. The 1,520 and $1,435 \mathrm{~mm}$ track gauges connect in the large transport hubs of Kaliningrad and Chernyakhovsk. Seven railroads meet in Kaliningrad and four railroads in Chernyakhovsk. Trains are transferred from the $1,520 \mathrm{~mm}$ to the $1,435 \mathrm{~mm}$ track at the border crossings between Russia and Poland located in the Kaliningrad Region: two land railroad border checkpoints with Lithuania (Kybartai/Chernyshevskoe and Pagegiai/Sovetsk) on the 1,520 $\mathrm{mm}$ track gauge and two such points with Poland (Mamonovo/Braniewo and Zheleznodorozhny/Skandawa) on the 1,435 mm track gauge [4]. Mamonovo-Braniewo border checkpoint between Russia and Poland is covered by the Transport and Logistics Center 'Kaliningrad'. Transit cargoes headed for the Central and Northern Europe.

Reaching the Logistic Center all cargoes, including containers, heavy load and bulk, are transferred from freight $\mathrm{mm}$

Terminal is equipped with a cargo storage ground with capacity of 1200 TEU and 100 thousand tons in bulk (simultaneously) as well as with tools and equipment allowing to process 210 thousand TEU and 2 million tons cargo a year.All customs, phytocontrol and veterinary documents are prepared, processed and cleared within the Center's terminals.

Zheleznodorzhny-Skandawa border checkpoint between Russia and Poland is covered by the Transport and Logistics Center 'Chernyakhovsk' . Transit cargoes headed for the south-eastern Europe. Reaching the Center all cargoes, including containers, heavy load, bulk and automobiles, are transferred from freight wagons track size $1520 \mathrm{~mm}$ to wagons track size $1435 \mathrm{~mm}$. Terminal is equipped with an open-air cargo storage ground with capacity of 800 TEU, 15 thousand tons in bulk and 4.5 thousand automobiles (simultaneously) as well as with tools and equipment allowing to process 280 thousand TEU, 1.5 million tons cargo and 150 thousand cars a year.

The Port of Kaliningrad is the only warm-water port operating in the Baltic Sea. The region has a direct entry into Northern and Central Europe. The Kaliningrad Region area is 15,100 sq. $\mathrm{km}$. It is characterized by a small span, which is advantageous for transit traffic between Russia and Western Europe [5]. The distance to the biggest European

ports such as Gdansk, Hamburg, Antwerp, Stockholm is from 80 to 900 nautical miles. Voyage time: 10 hours to 2 days. Port terminals have capacity of processing 450 thousand TEU, 40 million tons general and oil cargoes and are equipped with facilities and technical equipment allowing transshipping of containers, fertilizers, oil and oil products, grains.

The region has the statuses of a special economic zone and a free economic zone. This has contributed to the favorable administrative, tax, and customs regimes and an opportunity to provide logistics services. The high logistics service quality is achieved by modern transport and logistics centers Kaliningrad and Chernyakhovsk.

The Kaliningrad Transport and Logistics Center services transit cargo traffic to Northern and Central Europe and specializes in heavy and bulk cargo and containers. Customs, phytosanitary, and veterinary documents are issued there (Fig. 1). 


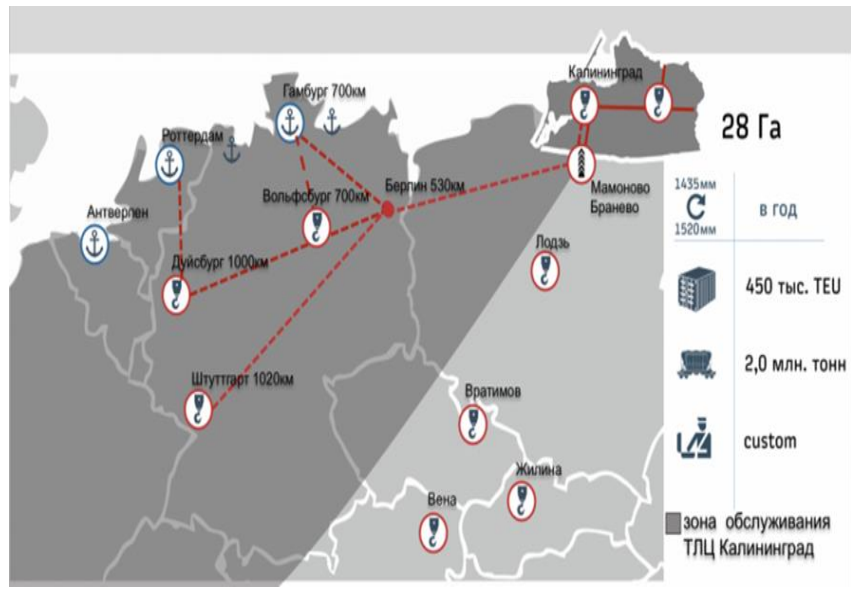

Fig. 1. The main cargo traffic routes through the Kaliningrad Transport and Logistics Center [6]

The Chernyakhovsk Transport and Logistics Center services cargo traffic to Southern and Eastern Europe. In addition to heavy and bulk cargo, it handles motor vehicles and refrigerator containers and issues all types of supporting documents. Much attention is paid to improving the door-todoor delivery services provided to cargo owners - the cargo is delivered by road to railroad stations and then transported internationally; or the arriving cargo is delivered by truck to the consignee's warehouse.

The factors that negatively impacted the Kaliningrad Region's transport potential included the complexity and duration of customs procedures in international trade. We need to simplify and speed up the customs procedures to raise the service quality in cargo supply chains and create conditions that will accelerate the flow of goods [7]. All customs checkpoints in the Kaliningrad Region use the autoregistration technology. Introducing electronic declarations and automating customs operations eliminated the need for personal attendance by international trade participants when declaring goods. Preliminary declaration before the actual arrival of goods and vehicles at customs checkpoints is also possible. All these measures simplify and accelerate the customs control, increase the throughput capacity of the customs checkpoints, and speed up cargo delivery. [8].

JSC Russian Railways has developed a set of anti-crisis measures aimed at maximum simplification of planning freight volumes [9]. To support industrial enterprises whose products are oriented at transport by railroad, the time for clearing consignors' requests for direct rail transport has been reduced to 2 days, and for direct international transport with the CIS and Baltic countries - to 3 days. Cargo can be stored at a warehouse with a deferred freight payment with a bank guarantee. The ETRAN (Electronic Way Bill) system aimed at long-distance traffic is under development. It improves the interaction of consignors and railroad personnel and enables signing cargo transportation requests and way bills with a digital signature.

The maritime transport infrastructure also needs to be developed alongside rail transport. The Kaliningrad Port is connected by international container lines with the ports in
England, Germany, Belgium, Denmark, Finland, the Netherlands, and the Baltic countries. But the shallow depth of up to 8 meters at the wharfs is a limiting factor, as it cannot accommodate vessels with the cargo capacity of over 15,000 tons or ocean ships. The Ust-Luga (Russia) - Sass Nitz (Germany) train ferry line is currently in operation. The port infrastructure in the Kaliningrad Region is ready for multimodal transportation along the East — West European corridor and to the Nordic countries and provides the required service level. A dry port near Chernyakhovsk is planned for construction to serve the increasing cargo traffic and improve the ship and cargo service quality. The project involves the creation of a large transport and logistics center which may become a part of the New Silk Road and participate in the distribution of cargo transported from China to Europe and back [10].

The Sea Port Portal access control system is currently functioning to accelerate the maritime cargo transport logistics, minimize cargo storage expenses in the customs control zone, and reduce the cargo storage time at the Kaliningrad Port. Its operation is based on the one-stop-shop principle and provides electronic information exchange between all transportation process participants.[11]

The Kaliningrad Region has a well-developed air transport infrastructure. The Khrabrovo International Airport serves domestic and international air traffic, flights to destinations such as Rome, Warsaw, Barcelona, and accommodates all types of Russian- and foreign-made planes, including business aviation. The airport has a cargo terminal equipped for land cargo processing that operates 24/7. The technical airport infrastructure is under constant development. Higherperformance equipment is purchased, accelerating cargo processing and improving customer service.

Thus, the Kaliningrad Region has a competitive potential for better-quality service in international cargo supply chains. Thus, the study evaluates the claim that the Kaliningrad region has a competitive potential for improving service in international cargo supply chains.

The aim of the study is to identify opportunities for developing increasing transit cargo traffic between Russia and Europe and improving service in cargo supply chains.

The methods of this study include a systematic approach, scientific abstraction, deduction and induction, economic analysis, data comparison, detalization, and grouping methods, graphing and tabulation, and forecasting methods.

The systematic approach and economic analysis enabled a comprehensive consideration of the regional economic development focused on servicing Russia's foreign trade and its transport and transit potential. The regional transport infrastructure condition and its key development problems were analyzed. A sample study was conducted of the development of transport infrastructure and the level of service within the Kaliningrad region. This sample is due to the unique position of the Kaliningrad region in the Russian Federation. Graphs and tables provided a better data visualization. The forecasting method was used to evaluate the 
underway and are included in the regional development programs. The positive outcome of accelerated delivery will be a reduced number of marshalling operations in yards (this does not concern unit trains). This is confirmed by the following calculations.

On average, train detention at a yard is $t=10$ hours with marshalling and 2 hours without marshalling (according to JSC Railway Research Institute). If the number of marshalling operations decreases, the cargo delivery time will shorten but the freight car-hours of accumulation ( $\mathrm{Va}$ ) at a station will increase by:

$$
V_{a}=C^{*} m
$$

where $\mathrm{C}$ is the accumulation ( 8 is the accepted mean value); $\mathrm{m}$ is the number of cars in a train which is determined by dividing the gross weight of the train by the gross weight of a loaded car.

If the number of cars in a train is 60 , the $\mathrm{V}_{\mathrm{a}}=8 * 60=480$ freight car-hours.

The reduction of freight car-hours for the calculated average daily freight-rail traffic volume $\left(\mathrm{N}_{\mathrm{mar}}\right)$ for one marshalling $\left(\mathrm{V}_{\mathrm{m}}\right)$ is:

$$
V_{m}=t_{\text {mar }} * N_{\text {mar }}
$$
goods and attention away from the problems of the Kaliningrad Region;

3. Higher competition between the Russian regions for budget funds;

4. A negative impact on the region's competitiveness of the high temporal and financial expenditures on crossing three borders (Lithuanian-Belarussian, Lithuanian-Russian, Belarussian-Lithuanian) due to cargo turnover slowdown, and costs in the European direction connected with an additional check for cargo transit formalities (insurance, transit declaration, veterinary and phytosanitary control, delivery guarantee);

5. Noncompetitive railroad rates - they are $40 \%$ higher in the direction from the Kaliningrad Region to Russia than the railroad rates for a similar distance within Russia. In addition, there is the problem of high transit costs through Lithuania and Belarus;

6. Regular transport and logistics complex operation problems. The issue can be solved by creating a regional macro-logistic system, including a transport hub, infrastructure facilities, developed transport and logistics communications, and a complex of logistics centers with the use of state-of-the-art digital technologies to process material, information, and financial flows. Improving the logistics system will shorten the order processing time and reduce costs.

A way to improve customer service and the Kaliningrad Region's attractiveness for cargo owners is accelerating rail cargo delivery. Faster delivery can become a reality due to the infrastructural and organizational changes that are currently where $t_{\mathrm{mar}}=10-2=8$ hours

$$
N_{\text {mar }}=Q / 365 * q,
$$

where Q is the annual freight volume (according to the 2018 data -15.7 million tons for the Kaliningrad railroad); $q$ is the railroad car capacity (60 tons);

$$
\begin{aligned}
& N_{\text {mar }}=15,700,000 / 365 * 60=716 \text { cars } \\
& V_{m}=8 * 716=5,728 \text { freight car }- \text { hours } .
\end{aligned}
$$

The necessary profitability condition for reducing marshalling operations is:

$$
V_{n}<V_{m}
$$
freight car-hours, i.e. the condition is met and it is profitable to reduce marshalling operations.

The total delivery time saved by eliminating just 1 marshalling per day will be:
In this calculation, $V_{n}=480$ freight car-hours, $V_{m}=5,728$ 
The position of the authors is supported by the opinion of

$\Delta V_{s}=V_{m}-V_{n}=5,728-480=5,248$ freight car - hours,

which is equal to the delivery time reduction by:

$$
\Delta t=\Delta V_{s} / N_{\text {mar }}=5,248 / 776=7.3 \text { hours }
$$

The calculations show that the ongoing regional rail transport modernization will accelerate cargo delivery by 7 hours and, consequently, improve customer service.

The Kaliningrad transport complex development opportunities can also be realized via broader interaction with Belarusian Railway, which is planning transit transport of Russian petroleum products and fertilizers through the Kaliningrad regional ports. The cargo traffic from Belarus to the Kaliningrad Region is constantly growing. In 2018, the freight volume in this direction rose by about $15 \%$ compared to the previous year, and most of this volume was transit transport. To support this positive trend, it is planned to modernize the railroad infrastructure, adopt a flexible rate policy, and introduce state-of-the-art information technology, including switching to electronic legally binding transport documents for international transportation.

The transit potential of the Kaliningrad Region was analyzed, such as:

- the rail, maritime, road, and air transport infrastructure condition;

- the development prospects according to the state regional development programs;

- the legal regulation of foreign economic relations and international transportation that considers the Special Economic Zone and the Free Economic Zone statuses of the region.

The conducted analysis of the Kaliningrad Region's transit potential led to certain conclusions on the existing opportunities for developing the actual and prospective international cargo traffic and improving the service in the supply chains between Europe and Russia. The calculations confirmed that the train processing time could be reduced by decreasing downtime at yards due to infrastructure modernization and introduction of electronic document flow. The positive results are an acceleration of cargo delivery to customers, a reduction of car turnover time, and raising the competitiveness of the regional transport system.

\section{DISCUSSION}

The results obtained in the course of article preparation confirm the need for continued transport and logistics infrastructure development in the Kaliningrad Region. This is consistent with the State Program for the Transport System Development of the Kaliningrad Region, which notes that the transport system can malfunction at the junction of different types of transport, and these malfunctions should be eliminated by creating new infrastructure complexes. [12] E.I. Dyatlova, Minister of Infrastructure Development of the Kaliningrad Region, who emphasizes in article [13] that it is important to build new roads and railroads within the region, to develop vehicle and train ferry terminals in Baltiysk. program underestimates the specifics of the region that is disconnected from the country's main territory. This means that raising the recycling fee is a disincentive for purchasing foreign used vehicles, thus becoming a limiting factor for road transport growth. Road transport also takes more time with higher costs than on the main Russian territory.[14]

Therefore, the discussed issue of improving the service quality in cargo supply chains to/from Europe through the Kaliningrad Region remains urgent. The regional transport and logistics infrastructure is considered a "development corridor" in expanding the trade and economic relations with the European countries.

The authors contributed to the analysis of the problem of using the transit potential of the Kaliningrad region to improve service in global supply chains of foreign trade cargo. The uniqueness of the study is due to the use of a systematic approach to the development of all types of transport in the region, resulting in an emphasis on the need for the comprehensive development of the infrastructure of all types of transport for the development of promising freight flows. The reality of reducing the time of cargo delivery during the implementation of infrastructure projects is proved by calculations.

\section{REFERENCES}

[1] The Russian exclave of Kaliningrad. Challenges and limits of its integration in the Baltic region. [Electronic resource] URL: https://journals.openedition.org/cybergeo/26945\#abstract (accessed: 07.12.2019).

[2] E.I. Pavlova, A.Z. Zaryan, "Influence of stability of external and internal environment on efficiency of supply chains in Sustainable development: society, ecology, economy", proceedings of the XV international scientific conference, vol. 3, 2019, pp. 312 - 327.

[3] UTLC, Kaliningrad Railway and ports of Kaliningrad region implement project of multimodal transportation [Electronic resource] URL: https://www.utlc.com/en/news/utlc-kaliningrad-railway-and-ports-ofkaliningrad-region-implement-project-of-multimodal-transportat/.

[4] A.S. Gusakova, E.V. Cherpakova, "Topical issues of development of the transport complex of the Kaliningrad region", Collection of articles on the materials of the XII international scientific and practical conference, vol. 2, 2018.

[5] Official website of Khrabrovo Airport. [Electronic resource] URL kgd.aero/mediacenter/news/ (accessed: 21.10.2019).

[6] The volume of transit container traffic through Kaliningrad is planned to increase to 1.5 million by 2024 TEU// Virtual customs. [Electronic resource] URL: vch.ru/event/view.html?alias (accessed: 07.04.2019).

[7] S.G. Kumaneva, "Interaction with participants of foreign economic activity: experience of the Kaliningrad regional customs", 10th Baltic transport forum, 6-7 September 2018 [Electronic resource] URL: https://konfer.ru/events/14441/program/ (accessed: 23.10.2019).

[8] T. Blecker, C. Jahn, W. Kersten, Maritime Logistics in the Global Economy: Current Trends and Approaches, vol. 5, 2011, p. 313.
Meanwhile, the regional experts believe that the state 
[12] Kaliningrad port // Kaliningrad 365.ru. [Electronic resource] URL: kaliningrad365.ru/info/kaliningradskij-port.html (accessed: 22.10.2019).

[9] S.P. Vakulenko, P.V. Kurenkov, "Intermodal and multimodal transportation within transport corridors of Europe and Asia", Container business, vol. 9(60), 2016.

[10] A.S. Gusakova, E.V. Cherpakova, "Topical issues of development of the transport complex of the Kaliningrad region", Collection of articles on the materials of the XII international scientific and practical conference, vol. 2, 2018.

[13] Official website Of the government of the Kaliningrad region [Electronic resource] - URL: gov39.ru/news/101/140881/ (accessed: 10.10.2019).

[14] Customs code of the Eurasian economic Union // Consultant Plus. [Electronic resource] URL: www.consultant.ru/document/ (accessed: 11.10.2019).

[11] Isolated exclave or" sea gate " of Russia: future of Kaliningrad port // Rubaltic.ru. [Electronic

resource]

URL: www.rubaltic.ru/article/ekonomika-i-biznes/05102018izolirovannyy-eksklav-ili-morskie-vorota-rossii-budushcheekaliningradskogo-porta/ (accessed: 06.10.2019).

[15] I.S. Gumenyuk, T. Studzieniecki, Current and Prospective Transport Connections between Poland's Border Voivodeships and Russia's Kaliningrad Region, vol. 10(2), 2018, pp. 114-132, doi: 10.5922/20798555-2018-2-8. 